\title{
The administration of dextrose during in-hospital cardiac arrest is associated with increased mortality and neurologic morbidity
}

Teng J Peng ${ }^{1 \dagger}$, Lars W Andersen ${ }^{1,2 \dagger}$, Brian Z Saindon ${ }^{1}$, Tyler A Giberson ${ }^{1}$, Won Young Kim', Katherine Berg ${ }^{3}$, Victor Novack ${ }^{3,4}$, Michael W Donnino ${ }^{1,3^{*}}$ and for the American Heart Association's Get With The Guidelines ${ }^{\circledR}$-Resuscitation Investigators

\begin{abstract}
Introduction: Dextrose may be used during cardiac arrest resuscitation to prevent or reverse hypoglycemia. However, the incidence of dextrose administration during cardiac arrest and the association of dextrose administration with survival and other outcomes are unknown.

Methods: We used the Get With The Guidelines ${ }^{\oplus}$-Resuscitation national registry to identify adult patients with an in-hospital cardiac arrest between the years 2000 and 2010. To assess the adjusted effects of dextrose administration on survival, we used multivariable regression models with adjustment for multiple patient, event, and hospital characteristics. We performed additional analyses to examine the effects of dextrose on neurological outcome and return of spontaneous circulation.

Results: Among the 100,029 patients included in our study, 4,189 (4.2\%) received dextrose during cardiac arrest resuscitation. The rate of dextrose administration increased during the study period (odds ratio $1.11,95 \%$ confidence interval $(C I)$ 1.09-1.12 per year, $P<0.001$ ). Patients who received dextrose during resuscitation had lower rates of survival compared with patients who did not receive dextrose (relative risk $0.88,95 \% \mathrm{Cl} 0.80-0.98, P=0.02$ ). Administration of dextrose was associated with worse neurological outcome (relative risk $0.88,95 \% \mathrm{Cl} 0.79-0.99, P=0.03$ ) but an increased chance of return of spontaneous circulation (relative risk 1.07, 95\% Cl 1.04-1.10, $P<0.001$ ).

Conclusions: In this dataset, the administration of dextrose during resuscitation in patients with in-hospital cardiac arrest was found to be associated with a significantly decreased chance of survival and a decreased chance of good neurological outcome.
\end{abstract}

\section{Introduction}

In-hospital cardiac arrest (IHCA) is one of the leading causes of death in the United States, with an incidence of over 200,000 patients per year and a mortality rate of more than $75 \%$ [1]. Over the past decade, there have been enhancements to cardiac life support interventions, increased quality-improvement efforts, and improved

\footnotetext{
* Correspondence: mdonnino@bidmc.harvard.edu

${ }^{\dagger}$ Equal contributors

'Department of Emergency Medicine, Beth Israel Deaconess Medical Center, One Deaconess Road, W/CC 2, Boston, MA 02215, USA

${ }^{3}$ Department of Medicine, Division of Critical Care, Beth Israel Deaconess

Medical Center, Boston, MA, USA

Full list of author information is available at the end of the article
}

IHCA survival trends [2]. Nevertheless, the mortality rate for IHCA patients remains extremely high $[1,3,4]$.

In 2005, the American Heart Association guidelines for advanced cardiac life support (ACLS) [5] listed hypoglycemia as a reversible cause of cardiac arrest but removed it upon the publication of the current 2010 ACLS guidelines [6]. Pre-2005 editions of the ACLS guidelines have never included hypoglycemia as a reversible cause of cardiac arrest, and the provision of dextrose during cardiac arrest in the absence of confirmed hypoglycemia is not suggested in the current guidelines [7]. To date, the current 2010 ACLS guidelines recommend the use of dextrose with insulin to treat severe hyperkalemia and suggest that insulin with dextrose can be considered for

\section{Biomed Central}

(c) 2015 Peng et al.; licensee BioMed Central. This is an Open Access article distributed under the terms of the Creative Commons Attribution License (http://creativecommons.org/licenses/by/4.0), which permits unrestricted use, distribution, and reproduction in any medium, provided the original work is properly credited. The Creative Commons Public Domain Dedication waiver (http://creativecommons.org/publicdomain/zero/1.0/) applies to the data made available in this article unless otherwise stated. 
severe beta-blocker overdose, but neither support nor discourage the use of dextrose for any other condition $[6,8]$.

The use of dextrose in cardiac arrest has not been adequately studied in the clinical setting, and the incidence of dextrose administration remains unknown [9]. Experimental evidence has suggested that dextrose administration might be harmful. Animal studies have shown that administering dextrose before, during, or after cardiac arrest leads to higher rates of mortality and worse neurological outcome [10-12]. In a study using pigs, hyperglycemia prior to cardiac arrest was associated with increased ischemic brain injury and increased markers of cerebral injury [13]. Similarly, human studies have shown that higher post-arrest blood glucose levels are associated with increased mortality and poor neurological outcome [14-20]. Hyperglycemia is also an independent predictor of mortality in myocardial infarction and stroke [21,22].

We hypothesized that the administration of dextrose during cardiac arrest resuscitation would be associated with higher post-arrest mortality and worse neurological outcome. To test this hypothesis, we used a large national registry of IHCAs to establish the rate of dextrose administration during cardiac arrest. We then compared the survival with discharge of patients who received dextrose with patients who did not receive dextrose during cardiac arrest resuscitation. Secondarily, we assessed the association between dextrose administration and return of spontaneous circulation (ROSC) and neurological outcome.

\section{Methods}

\section{Data source}

The Get With The Guidelines-Resuscitation (GWTG-R) registry, formerly known as the National Registry of Cardiopulmonary Resuscitation, is a national, prospective, quality-improvement registry of IHCAs and is sponsored by the American Heart Association. The GWTG-R design for data collection and reliability has been described previously in detail [23]. In brief, trained research personnel at participating hospitals collect data on all IHCA patients who do not have prior do-not-resuscitate orders or cardiopulmonary resuscitation events that began outside of the hospital. Cardiac arrest is defined as pulselessness requiring chest compressions or defibrillation or both, with a hospital-wide or unit-based emergency response by acute care facility personnel. Cases are identified and data are extracted from cardiac arrest flow sheets, reviews of hospital paging system logs, routine checks of code carts, pharmacy drug records, and hospital billing charges for resuscitation medication [23].

To facilitate uniform reporting across hospitals, the registry employs Utstein-style templates for cardiac arrest, a set of standardized reporting guidelines used to define patient variables and outcomes [24,25]. Further integrity of the data is ensured through rigorous certification of data entry personnel and the use of standardized software that checks the data for completeness and accuracy [26]. All participating hospitals are required to comply with local regulatory guidelines. Because data are used primarily at the local site for quality improvement, sites are granted a waiver of informed consent under the common rule. The institutional review board at Beth Israel Deaconess Medical Center (Boston, MA, USA) reviewed the present study and determined that it did not meet the federal definition of human subject research.

\section{Study population}

Our cohort study includes data submitted to the GWTG-R registry between January 2000 and September 2010. We included all patients 18 years or older. To secure the accuracy of the data, we excluded cases from hospitals with high rates of missing data, defined as an average rate of missing data for variables in our model of more than $10 \%$. We also excluded cases from hospitals with fewer than five cases per year, fewer than a total of 20 reported cases, less than one year of reporting, and cases with missing hospital data. Non-index events and events without initiation of cardiopulmonary resuscitation were excluded. Patients with missing data on dextrose administration and patients who simultaneously received dextrose and insulin (recommended treatment for presumed hyperkalemia) were also excluded (Figure 1).

\section{Study outcomes}

The exposure variable, administration of dextrose, was defined as any administration of a dextrose bolus without concurrent administration of insulin during the cardiac arrest. Dextrose administration before or after the event was not included. The primary outcome of interest was survival to discharge. Secondary outcomes were good neurological outcome at the time of hospital discharge and ROSC, defined as at least 20 minutes with a palpable pulse. Neurological outcome was assessed with the use of the cerebral performance category (CPC) score, in which a CPC score of 1 indicates mild or no neurological deficit, 2 moderate cerebral disability, 3 severe cerebral disability, 4 coma or vegetative state, and 5 brain death [27]. A CPC score of 1 or 2 was considered a good neurological outcome, and a CPC score of 3 to 5 or death was considered a bad neurological outcome.

\section{Statistical analysis}

The study population was characterized by using descriptive statistics. Categorical variables are provided in frequencies and continuous variables in means with standard deviation or medians with interquartile range (IQR), depending on the normality of the data. Differences between variables were evaluated by using chi-squared 


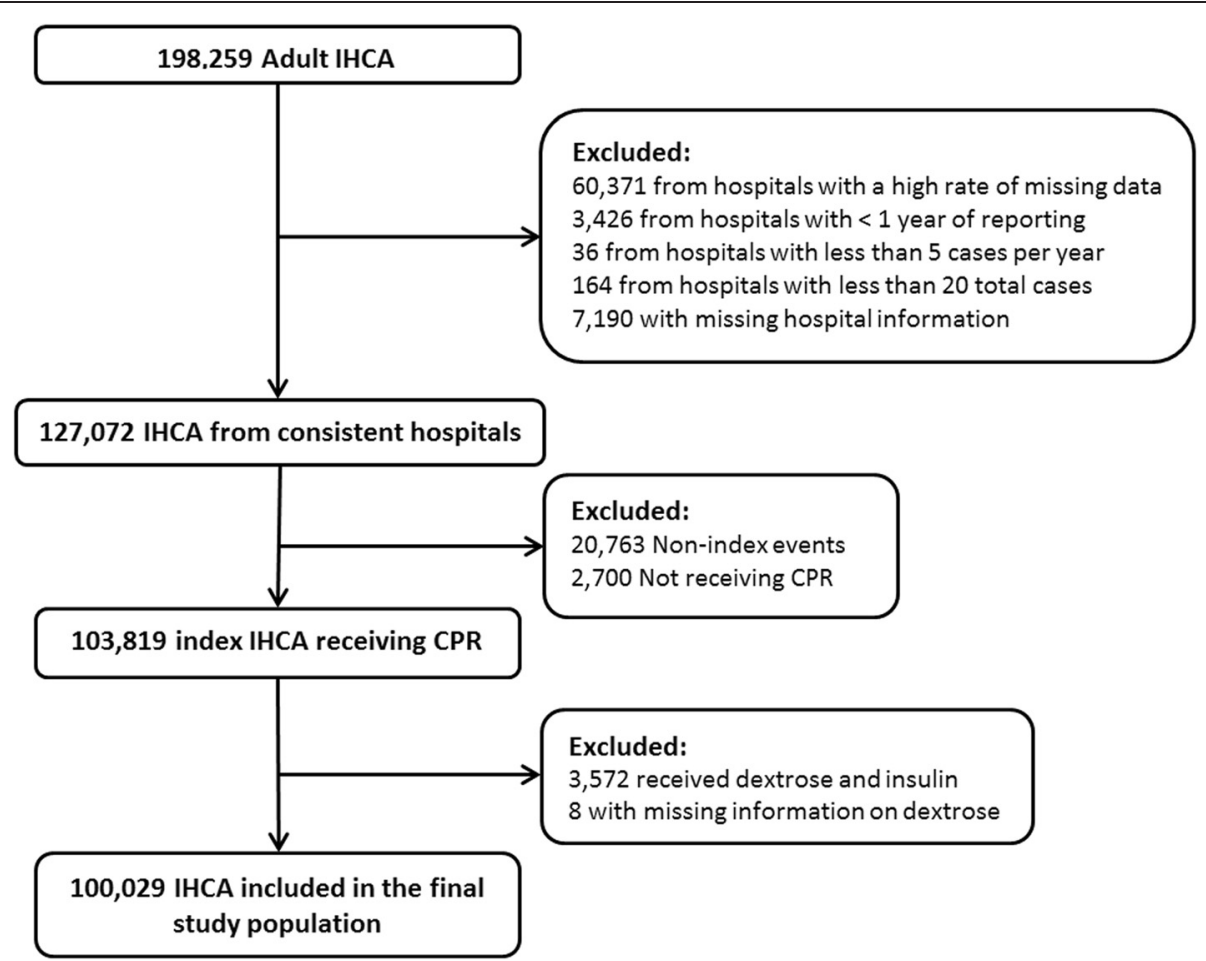

Figure 1 Study population. In total, 98,230 cardiac arrests were excluded, leaving 100,029 cardiac arrests from 349 hospitals. CPR, cardiopulmonary resuscitation; IHCA, in-hospital cardiac arrest.

tests for categorical variables and Wilcoxon rank-sum tests for continuous variables. The change in incidence of dextrose administration over time (treated as a continuous variable for this analysis) was assessed by using unadjusted logistic regression, and the result is presented as an odds ratio (OR) with $95 \%$ confidence interval $(\mathrm{CI})$.

To assess the independent association between dextrose administration during cardiac arrest resuscitation and survival to discharge, we used multivariable regression models with generalized estimating equations with an exchangeable (compound symmetry) correlation matrix to account for hospital clustering. Since the outcome was not rare (>10\%), we used modified Poisson regression models with robust variance estimates to estimate risk ratios (RRs) as described by Zou [28] and Zou and Donner [29] and previously used in this cohort $[2,30]$. In our model, we adjusted for age, gender, race, coexisting conditions, arrest characteristics (including presumed cause of the arrest and initial rhythm), interventions during the arrest, and selected hospital characteristics (see Additional file 1: Table S1 for a full list of variables). Year of arrest was entered in the model as a categorical variable with year 2000 as the reference. All variables were chosen $a$ priori on the basis of prior work and clinical reasoning [2,26,30-33]. Similar multivariate regression models were used to analyze secondary outcomes. Results from the multivariable regression models are reported as RRs with 95\% CIs.
The rate of missing data in the study cohort was low $(<1 \%)$ except for race (7.0\%), initial rhythm (5.7\%), downtime (4.7\%), time of day (1.3\%), and neurological outcome (2.6\%). To account for missing data, we imputed the median value for patients of the same gender for all observations with missing covariates. We then did the multivariate logistic regression including the imputed values for those missing covariates. The point estimates for the variables included in the models with and without imputation were similar, and thus we have reported non-imputed models.

To determine the association between dextrose administration and post-resuscitation survival, we conducted a subgroup analysis on all patients who achieved ROSC. We performed a sensitivity analysis in which all patients with a downtime (see Additional file 1: Table S1 for a precise definition) of 5 minutes or less (to avoid confounding by potential survival bias) or with more than 10 minutes of downtime were excluded (to avoid the possibility that administration of glucose was purely a function of longer downtime). To further ensure that the patients who received dextrose were not being treated for hyperkalemia, we conducted a subgroup analysis excluding all patients who received calcium chloride or calcium gluconate. To test for effect modification, we conducted a pre-planned stratified analysis based on coexisting diabetes. We performed a number of post hoc analyses to assess other 
potential subgroup differences. We assessed interaction terms in the main model between dextrose administration and the following: cardiac cause of the arrest defined as active/evolving myocardial infarction or arrhythmia (yes/no), cardiac reason for admission (yes/no), no coexisting sepsis or hepatic insufficiency (yes/no) (that is, potential reasons for hypoglycemia in a non-diabetic patient), location of the arrest (ICU versus non-ICU), and coexisting metabolic/electrolyte abnormalities within 4 hours of the arrest (inclusive of hypoglycemia), or presumed cause of the arrest as metabolic/electrolyte abnormality (yes/no).

To assess the robustness of our findings, we performed a propensity-matched adjusted analysis to test the association between glucose administration and each outcome. For the propensity-matched analysis, we used the imputed dataset and included all variables that had been included as independent variables in the primary analysis as well as hospital center. Next, we performed a 1:3 propensity score match between patients administered and not administered glucose by using an algorithm match caliper radius of 0.10 around the propensity score. We confirmed that the matched groups were balanced by ensuring that the standardized differences between groups for each covariate were less than 10. There was a small but statistically significant difference between cases and controls for three variables (Additional file 2: Table S2). With the 1:3 propensity-matched dataset, associations between glucose administration and outcomes were assessed with the Cochran-Mantel-Haenszel test to ensure comparison between matched pairs. Using these three variables, we performed an adjusted and unadjusted conditional logistic regression analysis. There was a less than $4 \%$ change in the point estimates (adjusted versus unadjusted), and the unadjusted results are presented here. Results from the propensity-matched analysis are reported as OR with $95 \%$ CIs.

Statistical analyses were conducted with SAS software version 9.3 (SAS Institute Inc., Cary, NC, USA). All hypothesis tests were two-sided, and a $P$ value of less than 0.05 was considered significant.

\section{Results}

\section{Characteristics of the study population}

In total, 100,029 IHCAs from 349 hospitals were included in the main analysis (Figure 1). The median age was 69 (IQR 57-79), and 42\% were female. Additional patient, arrest, and hospital characteristics are shown in Tables 1 and 2. Administration of dextrose occurred in 4,173 (4.2\%) cardiac arrests. There was a significant increase in the incidence of dextrose administration from 2000 (2.5\%) to 2010 (5.7\%) (OR 1.11, 95\% CI 1.09-1.12 per year, $P<0.001)$ (Figure 2).

\section{Primary outcome}

Eighteen point six percent of patients survived to hospital discharge. Patients who received dextrose during cardiac arrest resuscitation had a lower rate of survival to discharge compared with patients who did not receive dextrose (RR 0.49, 95\% CI 0.44-0.54, $P<0.001$ ). After multivariable adjustment, dextrose was still associated with a significantly decreased chance of survival to discharge (RR 0.88, 95\% CI 0.80-0.98, $P=0.02$ ) (Figure 3). See Additional file 3: Table S3 for the full model.

\section{Secondary outcomes}

Fifty-eight point two percent of patients achieved ROSC, and $13.7 \%$ of patients with full data had a good neurological outcome at hospital discharge (an additional 2.6\% survived but had missing data on neurological outcome). In unadjusted analyses, administration of dextrose was associated with decreased chance of ROSC (RR 0.92, 95\% CI 0.88-0.96, $P<0.001)$ and decreased chance of good neurological outcome (RR 0.43, 95\% CI 0.38-0.49, $P<0.001)$. After multivariable adjustment, dextrose administration was associated with an increased chance of ROSC (RR 1.07, 95\% CI 1.04-1.10, P<0.001) and a decreased chance of good neurological outcome (RR 0.88 , 95\% CI 0.79-0.99, $P=0.03$, Figure 3 ).

To further characterize the association between administration of dextrose and post-resuscitation survival, we conducted a subgroup analysis including only patients who obtained ROSC. In this subgroup, our multivariable analysis showed that administration of dextrose was still associated with both decreased chance of survival to discharge (RR 0.84, 95\% CI 0.77-0.92, $P<0.001$ ) and decreased chance of good neurological outcome (RR 0.84, 95\% CI 0.76-0.93, $P=0.001)$. In our sensitivity analysis of patients with a downtime between 5 and 10 minutes, we found that dextrose was associated with an increased chance of ROSC (RR 1.06, 95\% CI 1.01-1.10, $P=0.008$ ), a strong trend toward decreased chance of survival (RR 0.83, 95\% CI 0.68-1.01, $P=0.06)$, and decreased chance of good neurological outcome (RR 0.78, 95\% CI 0.62-0.99, $P=0.04$ ).

We conducted a pre-planned analysis in order to investigate potential effect modification by coexisting diabetes (type I or type II). Thirty point six percent of the overall population had documented diabetes, and dextrose was more commonly administered in patients with diabetes than in patients without diabetes (5.6\% versus $3.5 \%, P<0.001)$. There was a significant interaction between dextrose administration and diabetes status with survival as outcome $(P=0.02)$ but not with ROSC $(P=0.46)$ or good neurological outcome $(P=0.23)$ as the outcome measure. In patients with diabetes, administration of dextrose was not associated with survival to discharge (RR 0.94, 95\% CI 0.83-1.07, $P=0.32$ ), whereas in patients without diabetes, the administration 
Table 1 Characteristics of the study population according to dextrose administration

\begin{tabular}{|c|c|c|c|}
\hline \multirow[t]{3}{*}{ Characteristic } & \multicolumn{2}{|c|}{ Received dextrose during cardiac arrest } & \multirow[t]{3}{*}{$P$ value } \\
\hline & No & Yes & \\
\hline & $(n=95,856)$ & $(n=4,173)$ & \\
\hline \multicolumn{4}{|l|}{ Demographics } \\
\hline Age in years, median (IQR) & $69(57-79)$ & $65(53-77)$ & $<0.001$ \\
\hline Sex, number (percentage) & & & 0.03 \\
\hline Female & $40,306(42.1)$ & $1,690(40.3)$ & \\
\hline Male & $55,550(58.0)$ & $2,499(59.7)$ & \\
\hline Race, number (percentage) & & & $<0.001$ \\
\hline White & $68,474(76.8)$ & $2,527(64.8)$ & \\
\hline Black & $17,109(19.2)$ & $1,208(31.0)$ & \\
\hline Other & $3,551(4.0)$ & $165(4.2)$ & \\
\hline Type of admission, number (percentage) & & & $<0.001$ \\
\hline Medical-Non-cardiac & $41,798(43.6)$ & $2,267(54.3)$ & \\
\hline Medical-Cardiac & $32,031(35.4)$ & $1,212(29.1)$ & \\
\hline Surgical-Non-cardiac & $10,877(11.4)$ & $421(10.1)$ & \\
\hline Surgical-Cardiac & $6,188(6.5)$ & $185(4.4)$ & \\
\hline Trauma & $2,777(2.9)$ & $73(1.8)$ & \\
\hline Other & $272(0.3)$ & $14(0.3)$ & \\
\hline \multicolumn{4}{|l|}{ Pre-existing conditions, number (percentage) } \\
\hline \multicolumn{4}{|l|}{ Cardiac } \\
\hline Arrhythmia & $31,414(32.9)$ & $1,188(28.5)$ & $<0.001$ \\
\hline History of Ml & $15,864(16.6)$ & $584(14.0)$ & $<0.001$ \\
\hline Ml this admission & $17,148(17.9)$ & $472(11.3)$ & $<0.001$ \\
\hline History of heart failure & $20,090(21.0)$ & $911(21.9)$ & 0.19 \\
\hline Heart failure this admission & $17,091(17.9)$ & $702(16.8)$ & 0.08 \\
\hline \multicolumn{4}{|l|}{ Non-cardiac } \\
\hline Respiratory insufficiency & $40,001(41.9)$ & $1,672(40.2)$ & 0.03 \\
\hline Diabetes mellitus & $28,759(30.1)$ & $1,717(41.2)$ & $<0.001$ \\
\hline Renal insufficiency & $30,784(32.2)$ & $1,838(44.0)$ & $<0.001$ \\
\hline Metastatic/Hematologic malignancy & $11,801(12.4)$ & $471(11.3)$ & 0.05 \\
\hline Hypotension/Hypoperfusion & $26,263(27.5)$ & $1,107(26.6)$ & 0.21 \\
\hline Pneumonia & $13,015(13.6)$ & $592(14.2)$ & 0.30 \\
\hline Baseline depression in CNS function & $12,273(12.8)$ & $564(13.5)$ & 0.18 \\
\hline Metabolic/Electrolyte abnormality & $15,477(16.2)$ & $974(23.3)$ & $<0.001$ \\
\hline Septicemia & $14,586(15.3)$ & $872(20.9)$ & $<0.001$ \\
\hline Acute CNS non-stroke event & $6,991(7.3)$ & $314(7.5)$ & 0.58 \\
\hline Hepatic insufficiency & $6,724(7.0)$ & $431(10.4)$ & $<0.001$ \\
\hline Acute stroke & $3,686(3.9)$ & $144(3.5)$ & 0.18 \\
\hline Major trauma & 3,587 (3.8) & $104(2.5)$ & $<0.001$ \\
\hline
\end{tabular}

CNS, central nervous system; IQR, interquartile range; MI, myocardial infarction.

of dextrose was associated with a decreased chance of survival (RR 0.80, 95\% CI 0.69-0.94, $P=0.005$ ) (Figure 4). After exclusion of patients who received calcium chloride or calcium gluconate, the association between dextrose administration and mortality remained (RR 0.88, 95\% CI $0.78-0.98, P=0.02$ ). None of the other interaction terms tested (see Methods section) was statistically significant, indicating no subgroup differences. 
Table 2 Arrest and hospital characteristics according to dextrose administration

\begin{tabular}{|c|c|c|c|}
\hline \multirow[t]{3}{*}{ Characteristic } & \multicolumn{2}{|c|}{ Received dextrose during cardiac arrest } & \multirow[t]{3}{*}{$P$ value } \\
\hline & No & Yes & \\
\hline & $(n=95,856)$ & $(n=4,173)$ & \\
\hline \multicolumn{4}{|l|}{ Location and time of the arrest, number (percentage) } \\
\hline Location & & & $<0.001$ \\
\hline Floor without telemetry & $15,855(16.6)$ & $1,025(24.6)$ & \\
\hline Floor with telemetry & $16,710(17.4)$ & $730(17.5)$ & \\
\hline Intensive care unit & $45,011(47.0)$ & $1,597(38.3)$ & \\
\hline Emergency department & $10,363(10.8)$ & $544(13.0)$ & \\
\hline Other & $6,974(7.6)$ & $276(6.6)$ & \\
\hline Time of day & & & $<0.001$ \\
\hline Day (7 a.m. -10:59 p.m.) & $63,897(67.6)$ & $2,666(64.5)$ & \\
\hline Night (11 p.m.-6:59 a.m.) & $30,673(32.4)$ & $1,467(35.5)$ & \\
\hline Time of week, number (percentage) & & & 0.30 \\
\hline Weekday (Monday-Friday) & $65,269(68.8)$ & $2,818(68.0)$ & \\
\hline Weekend (Saturday-Sunday) & $29,642(31.2)$ & $1,326(32.0)$ & \\
\hline Hospital-wide response called, number (percentage) & $76,720(80.0)$ & $3,361(80.5)$ & 0.40 \\
\hline \multicolumn{4}{|l|}{ Characteristic of the arrest } \\
\hline Monitoring, number (percentage) & $78,166(81.6)$ & $3,053(73.2)$ & $<0.001$ \\
\hline Witnessed, number (percentage) & $78,262(81.7)$ & $3,050(73.1)$ & $<0.001$ \\
\hline First rhythm shockable (VT or VF), number (percentage) & $18,340(20.3)$ & $517(13.0)$ & $<0.001$ \\
\hline Mechanical ventilation in place, number (percentage) & $27,928(29.1)$ & $1,103(26.4)$ & $<0.001$ \\
\hline Airway inserted during event, number (percentage) & $51,028(53.3)$ & $2,680(64.2)$ & $<0.001$ \\
\hline \multicolumn{4}{|l|}{ Presumed cause(s) of arrest, number (percentage) } \\
\hline Arrhythmia & $56,147(58.9)$ & $2,215(53.4)$ & $<0.001$ \\
\hline Hypotension/Hypoperfusion & $37,571(39.4)$ & $1,596(38.5)$ & 0.22 \\
\hline Active/Evolving Ml & $8,919(9.4)$ & $270(6.5)$ & $<0.001$ \\
\hline Acute respiratory insufficiency & $37,064(38.9)$ & $1,670(40.3)$ & 0.08 \\
\hline Metabolic/Electrolyte abnormality & $10,809(11.4)$ & $860(20.7)$ & $<0.001$ \\
\hline Other & $7,619(8.0)$ & $345(8.3)$ & 0.46 \\
\hline Unknown & $10,340(10.9)$ & $578(13.9)$ & $<0.001$ \\
\hline Downtime in minutes, median (IQR) & $12(6-21)$ & $18(10-27)$ & $<0.001$ \\
\hline \multicolumn{4}{|l|}{ Medications given during the event, number (percentage) } \\
\hline Amiodarone & $14,806(15.5)$ & $703(16.9)$ & 0.01 \\
\hline Epinephrine & $84,336(88.0)$ & $4,019(96.3)$ & $<0.001$ \\
\hline Atropine & $67,947(70.9)$ & $3,490(83.6)$ & $<0.001$ \\
\hline Magnesium sulfate & $7,156(7.5)$ & $567(13.6)$ & $<0.001$ \\
\hline Lidocaine & $10,152(10.6)$ & $381(9.1)$ & 0.003 \\
\hline Sodium bicarbonate & $43,775(45.7)$ & $3,111(74.6)$ & $<0.001$ \\
\hline Fluid bolus & 28,011 (29.2) & $1,452(34.7)$ & $<0.001$ \\
\hline Calcium chloride/gluconate & 20,188 (21.1) & $1,955(46.9)$ & $<0.001$ \\
\hline Norepinephrine & $12,500(13.0)$ & $675(16.2)$ & $<0.001$ \\
\hline Dopamine & 23,078 (24.1) & $1,037(24.1)$ & 0.25 \\
\hline
\end{tabular}


Table 2 Arrest and hospital characteristics according to dextrose administration (Continued)

\begin{tabular}{|c|c|c|c|}
\hline \multicolumn{4}{|c|}{ Hospital characteristics, number (percentage) } \\
\hline Bed size & & & $<0.001$ \\
\hline $1-249$ & $23,450(24.2)$ & $908(21.7)$ & \\
\hline 250-499 & $44,001(45.9)$ & $1,836(44.0)$ & \\
\hline $500+$ & $28,408(29.6)$ & $1,429(34.1)$ & \\
\hline Teaching status & & & $<0.001$ \\
\hline Major & $25,246(26.3)$ & $1,527(36.6)$ & \\
\hline Minor & $33,930(35.3)$ & $1,162(27.7)$ & \\
\hline Non-teaching & $36,680(38.2)$ & $1,484(35.4)$ & \\
\hline Ownership & & & $<0.001$ \\
\hline Private & $12,247(12.8)$ & $540(12.9)$ & \\
\hline Government & $14,407(15.0)$ & $899(21.5)$ & \\
\hline Non-profit & $69,202(72.2)$ & $2,734(65.5)$ & \\
\hline Location & & & $<0.001$ \\
\hline Rural & $6,274(6.5)$ & $216(5.2)$ & \\
\hline Urban & $89,582(93.5)$ & $3,957(94.8)$ & \\
\hline Geographical location & & & $<0.001$ \\
\hline North-East & $10,484(10.9)$ & 491 (11.7) & \\
\hline South-East & $26,019(27.1)$ & $1,125(26.9)$ & \\
\hline Mid-West & $23,539(21.0)$ & $1,099(26.9)$ & \\
\hline South-West & $19,998(20.9)$ & 864 (21.4) & \\
\hline West & $15,816(16.5)$ & $564(13.5)$ & \\
\hline
\end{tabular}

IQR, interquartile range; $P E A$, pulseless electrical activity; $V F$, ventricular fibrillation; $V T$, ventricular tachycardia.

\section{Results from the propensity-matched analysis}

The propensity matching resulted in a successful match of 4,171 patients administered dextrose to 12,498 patients who did not receive dextrose. The groups were well matched on covariates (Additional file 2: Table S2).

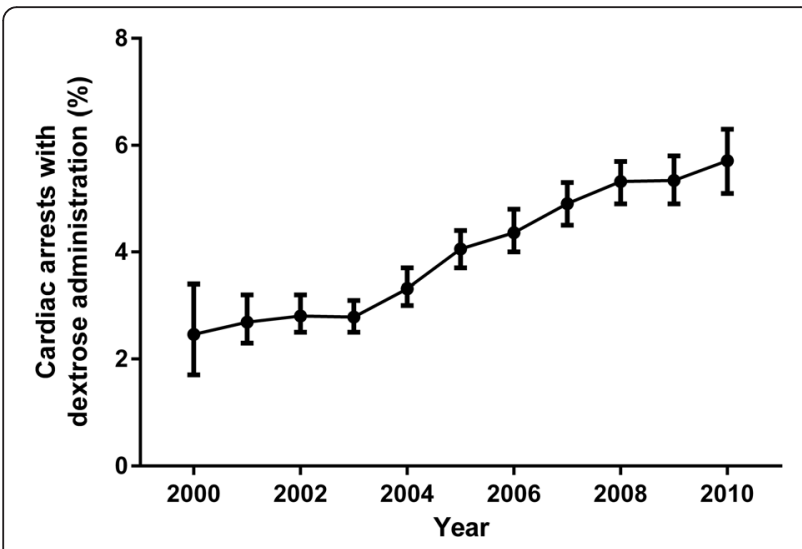

Figure 2 Incidence of dextrose administration over time. Percentage of cardiac arrests with dextrose administration over time. Error bars indicate exact binomial 95\% confidence intervals $(\mathrm{Cls})$. There was a steady increase in the incidence of dextrose administration from $2000(2.5 \%)$ to 2010 (5.7\%) (odds ratio 1.11, 95\% Cl 1.09-1.12 per year, $P<0.001)$.
With our propensity-matched dataset, administration of dextrose was associated with a significantly decreased chance of survival to discharge (OR 0.80, 95\% CI 0.71-0.90, $P<0.001$ ). Dextrose administration was likewise associated with a decreased chance of good neurological outcome (OR 0.79, 95\% CI 0.68-0.91, $P=0.001)$. However, the association between dextrose administration and ROSC was not significant when the propensity-matched analysis was used (OR 1.06, 95\% CI 0.99-1.13, $P=0.12$ ).

\section{Discussion}

In this large cohort study using the GWTG-R national database, we examined the association between dextrose administration and outcomes after cardiac arrest. We found that the use of dextrose during resuscitation is independently associated with lower rates of survival and unfavorable neurological outcomes. These associations remained significant even after multivariable adjustments and sensitivity analyses. The association between dextrose administration and lower rates of survival and unfavorable neurological outcomes furthermore remained in our propensity-matched analyses. In our primary analysis, dextrose administration was associated with slightly higher rates of ROSC; however, this association was no 


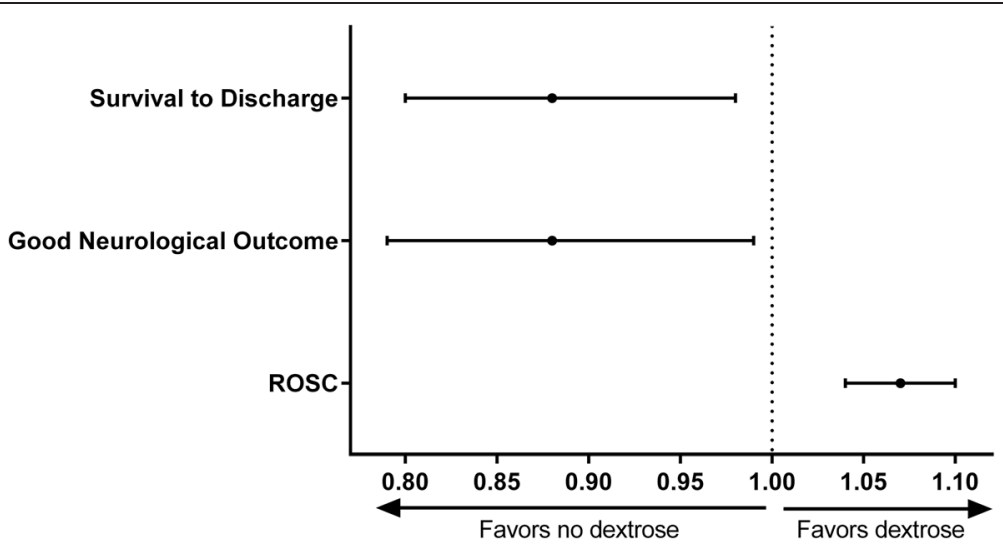

Figure 3 The association between dextrose administration and outcome. The association between administration of dextrose and survival to discharge, neurological outcome, and return of spontaneous circulation (ROSC). Adjusted risk ratios with 95\% confidence intervals are shown.

longer significant with propensity matching, making this finding difficult to interpret.

Although we cannot conclude from retrospective data why clinicians were giving dextrose during cardiac arrest, we would hypothesize that concern for hypoglycemia as the cause of arrest was likely a primary reason. Dextrose may also be administered out of concern that hypoglycemia is associated with higher mortality and potentially brain injury $[34,35]$. In dealing with a high-mortality event like cardiac arrest, clinicians are motivated to find and treat any potential reversible cause. With this in mind, in a truly hypoglycemic patient, the use of dextrose is probably recommended. However, studies have shown that hypoglycemia can be easily misdiagnosed in patients experiencing ischemic injuries. In current medical practice, a sample of capillary blood taken with a fingerstick blood glucose test is the quickest method to assess the possibility of hypoglycemia. However, studies have shown that fingerstick blood glucose measurements are inaccurate in patients in shock $[36,37]$ or cardiac arrest [38]. However, the use of venous blood with a bedside glucometer is accurate and could be used if deemed necessary.

The administration of dextrose in normoglycemic or hyperglycemic patients can lead to higher blood glucose levels. Patients with hyperglycemia after cardiac arrest [14-18] and other ischemic injuries (stroke [39] and head injury $[40,41]$ ) have longer recovery times and worse neurological outcomes. Traditionally, this elevation in blood glucose has been assumed to be part of a systemic stress response. The potential mechanisms behind elevated blood glucose levels and the association with poor outcome are not well understood. Prior studies have suggested that having higher blood glucose levels during periods of ischemia increases anaerobic metabolism, promotes the conversion of pyruvate into lactate, causes

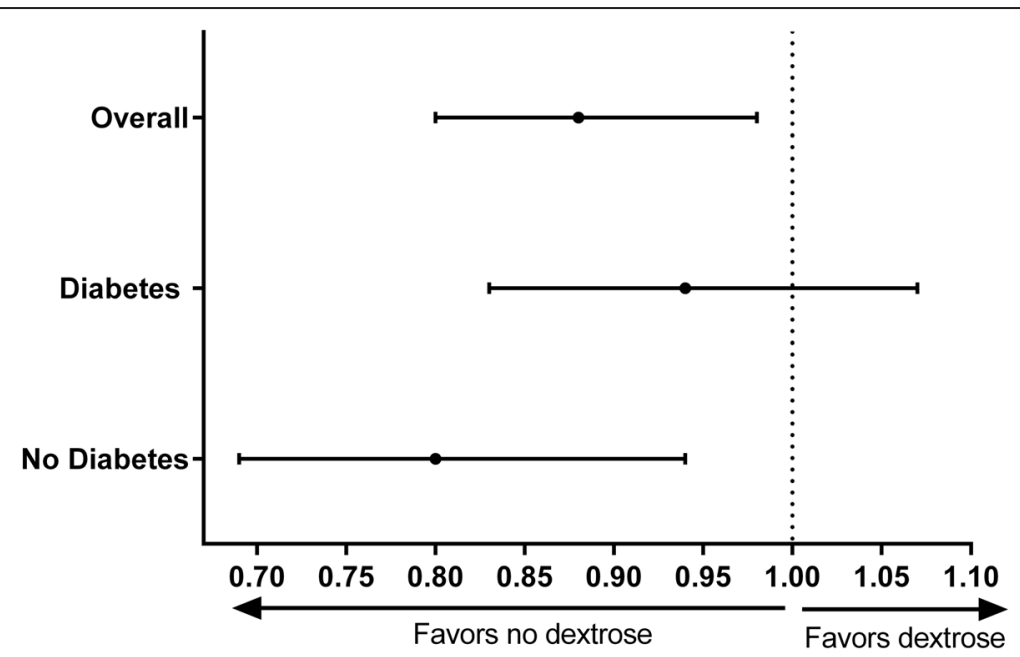

Figure 4 Dextrose, diabetes status, and survival. The association between administration of dextrose and survival to discharge was stratified by diabetes status. Adjusted risk ratios with 95\% confidence intervals are shown. 
intracellular acidosis, and may decrease cerebral blood flow, exacerbating cerebral ischemic injury [42-44]. Whether hyperglycemia plays a causal role in this process or is simply a marker of a systemic stress response or of dysfunctional metabolism at the cellular level is not clear.

One randomized study examined the relationship between dextrose administration after out-of-hospital cardiac arrest and neurological outcome and found no difference between the patients receiving 5\% dextrose and those receiving half normal saline [45]. However, the average dose of dextrose used in this study was low $(7 \mathrm{~g})$ compared with the usual bolus dose $(50 \mathrm{~mL})$ of $50 \%$ dextrose, which contains $25 \mathrm{~g}$ of dextrose. To date, no study has explored the relationship between the use of a dextrose bolus during cardiac arrest resuscitation and outcome.

Our subgroup analysis revealed that although the use of dextrose was associated with higher mortality in nondiabetic patients, the association was not significant in patients with diabetes. The resilience of patients with diabetes to the deleterious effects of acute hyperglycemia has been documented $[17,46]$. Having chronically elevated levels of blood glucose can cause structural and functional modifications, such as a greater buffering capacity and lower cerebral pH levels after induced cardiac arrest [47]. Chronic hyperglycemia has also been found to be partially protective against cerebral hypoxia caused by acute hyperglycemia [42]. The underlying mechanism of the potential protective effects of diabetes on acute hyperglycemia needs to be clarified in future studies. Another potential explanation for our findings is the higher rate of true hypoglycemia in diabetic patients for whom administration of dextrose would likely be beneficial.

The results of our study should be interpreted in the context of the following limitations. Even though the GWTG-R registry has a rigorous training and certification process and employs standardized definitions, the data acquired by the registry may contain data integrity and validity issues. Although the GWTG-R registry is large, participation is still voluntary and this raises the potential for selection bias. Also, GWTG-R is a quality-improvement registry and was not specifically tailored to study the effects of dextrose in cardiac resuscitation. Given the observational nature of the present study, we cannot exclude the possibility that unmeasured or residual confounding remains. We were unable to identify the reason why dextrose was administered, the dosage that was given, and the timing in which it was administered. In addition, information on whether patients were receiving dextrose-containing fluid before or after the event was not available, and glucose levels were not available for any patients. It is also possible that dextrose was more likely to be administered in patients in whom initial resuscitation attempts failed, giving them a poorer prognosis. However, we believe that we addressed this potential issue in multiple ways: downtime was included in our multivariable model, and our sensitivity analyses of cardiac arrests with downtime of between 5 and 10 minutes gave largely similar results as our primary analyses. Also, potential confounding by intra-arrest variables such as prolonged downtime or non-adherence to recommended protocols cannot explain the increased chance of ROSC seen in our primary analysis. The post-cardiac arrest population is a heterogeneous group. Despite our predefined and post hoc subgroup analyses, there still could be certain subgroups of patients for whom dextrose administration is beneficial. As always, patient care should be individually tailored to the clinical situation. Finally, given the exploratory nature of our analysis, the results should be verified in a prospective manner or in a dataset with more granular data (that is, reason for dextrose administration, timing of dextrose administration, and intra- and post-cardiac arrest glucose levels) or both before any conclusions regarding clinical practice can be made.

\section{Conclusions}

Although a causal relationship cannot be determined, our analysis shows that cardiac arrest patients receiving dextrose during resuscitation have a decreased chance of survival to hospital discharge and a decreased chance of good neurological outcome. This association seems to be driven primarily by an effect in the non-diabetic population.

\section{Key messages}

- The association between dextrose administration during cardiac arrest and survival is unknown.

- Dextrose is used in approximately $4.2 \%$ of all in-hospital cardiac arrests, with an increasing rate from 2000 to 2010.

- Patients who received dextrose during resuscitation had lower rates of survival compared with patients who did not receive dextrose, although whether this relationship is causal remains unproven.

- This association was maintained when using multivariable regression, sensitivity analyses, and a propensity-matched analysis.

- The association between dextrose administration and poor survival seems to be driven primarily by an effect in the non-diabetic population.

\section{Additional files}

Additional file 1: Table S1. Definitions of covariates and outcomes. Additional file 2: Table S2. Characteristics of propensity-matched groups.

Additional file 3: Table S3. Primary multivariable model: association between multiple variables and survival to discharge. 


\section{Abbreviations}

ACLS: advanced cardiac life support; CPC: cerebral performance category; GWTG-R: Get With The Guidelines ${ }^{\oplus}$-Resuscitation; IHCA: in-hospital cardiac arrest; IQR: interquartile range; OR: odds ratio; ROSC: return of spontaneous circulation; RR: risk ratio.

\section{Competing interests}

The authors declare that they have no competing interests.

\section{Authors' contributions}

TJP shared responsibility for study conception and design and helped to draft the manuscript. LWA shared responsibility for study conception and design, helped to perform statistical analyses, and helped to draft the manuscript. MWD shared responsibility for study conception and design. BZS and VN helped to perform statistical analyses. All authors took part in critical revision of the manuscript, interpreted the data, provided intellectual content, shared responsibility for revising the manuscript, and read and approved the final submission and agree to be accountable for all aspects of the work.

\section{Authors' information}

TJP and LWA are co-first authors.

\section{Acknowledgments}

MWD is supported by the National Heart, Lung, and Blood Institute (1K02HL107447-01A1) and the American Heart Association (14GRNT200100002). KB is supported by the American Heart Association (13CRP16930000).

\section{Get With The Guidelines ${ }^{\circledast}$-Resuscitation investigators}

Besides the author Michael W. Donnino, MD, members of the Get With The Guidelines ${ }^{\circledR}$-Resuscitation Adult Task Force include the following: Paul S. Chan, MD MSc, Saint Luke's Mid America Heart Institute; Steven M. Bradley MD, MPH, VA Eastern Colorado Healthcare System; Dana P. Edelson, MD, MS, University of Chicago; Robert T. Faillace, MD, ScM, Geisinger Healthcare System; Romergryko Geocadin, MD, Johns Hopkins University School of Medicine; Raina Merchant, MD, MSHP, University of Pennsylvania School of Medicine; Vincent N. Mosesso, Jr., MD, University of Pittsburgh School of Medicine; and Joseph P. Ornato, MD and Mary Ann Peberdy, MD, Virginia Commonwealth University.

\section{Author details}

${ }^{1}$ Department of Emergency Medicine, Beth Israel Deaconess Medical Center, One Deaconess Road, W/CC 2, Boston, MA 02215, USA. ²Department of Anesthesiology, Aarhus University Hospital, Aarhus, Denmark. ${ }^{3}$ Department of Medicine, Division of Critical Care, Beth Israel Deaconess Medical Center, Boston, MA, USA. ${ }^{4}$ Clinical Research Center, Soroka University Medical Centers, Beer-Shave, Israel.

\section{Received: 8 January 2015 Accepted: 9 March 2015}

\section{Published online: 10 April 2015}

\section{References}

1. Go AS, Mozaffarian D, Roger VL, Benjamin EJ, Berry JD, Blaha MJ, et al. Heart disease and stroke statistics-2014 update: a report from the American Heart Association. Circulation. 2014;129:e28-292.

2. Girotra S, Chan PS. Trends in survival after in-hospital cardiac arrest. N Engl J Med. 2013;368:680-1.

3. Ehlenbach WJ, Barnato AE, Curtis JR, Kreuter W, Koepsell TD, Deyo RA, et al. Epidemiologic study of in-hospital cardiopulmonary resuscitation in the elderly. N Engl J Med. 2009;361:22-31.

4. Bloom HL, Shukrullah I, Cuellar JR, Lloyd MS, Dudley Jr SC, Zafari AM. Long-term survival after successful inhospital cardiac arrest resuscitation. Am Heart J. 2007;153:831-6.

5. 2005 American Heart Association Guidelines for Cardiopulmonary Resuscitation and Emergency Cardiovascular Care. Part 7.2: Management of cardiac arrest. Circulation. 2005, 112:IV-58-IV-66.

6. Neumar RW, Otto CW, Link MS, Kronick SL, Shuster M, Callaway CW, et al. Part 8: adult advanced cardiovascular life support: 2010 American Heart Association Guidelines for Cardiopulmonary Resuscitation and Emergency Cardiovascular Care. Circulation. 2010;122:S729-67.
7. The American Heart Association in collaboration with the International Liaison Committee on Resuscitation. Guidelines for Cardiopulmonary Resuscitation and Emergency Cardiovascular Care. Part 6: advanced cardiovascular life support: section 1: Introduction to ACLS 2000: overview of recommended changes in ACLS from the guidelines 2000 conference. Circulation. 2000;102:186-9.

8. Vanden Hoek TL, Morrison L, Shuster M, Donnino M, Sinz E, Lavonas EJ, et al. Part 12: cardiac arrest in special situations: 2010 American Heart Association Guidelines for Cardiopulmonary Resuscitation and Emergency Cardiovascular Care. Circulation. 2010;122:S829-61.

9. Browning RG, Olson DW, Stueven HA, Mateer JR. 50\% dextrose: antidote or toxin? Ann Emerg Med. 1990;19:683-7.

10. Lundy EF, Kuhn JE, Kwon JM, Zelenock GB, D'Alecy LG. Infusion of five percent dextrose increases mortality and morbidity following six minutes of cardiac arrest in resuscitated dogs. J Crit Care. 1987:2:4-14.

11. Nakakimura K, Fleischer JE, Drummond JC, Scheller MS, Zornow MH, Grafe MR, et al. Glucose administration before cardiac arrest worsens neurologic outcome in cats. Anesthesiology. 1990;72:1005-11.

12. D'Alecy LG, Lundy EF, Barton KJ, Zelenock GB. Dextrose containing intravenous fluid impairs outcome and increases death after eight minutes of cardiac arrest and resuscitation in dogs. Surgery. 1986;100:505-11.

13. Molnar M, Bergquist M, Larsson A, Wiklund L, Lennmyr F. Hyperglycaemia increases S100beta after short experimental cardiac arrest. Acta Anaesthesiol Scand. 2014;58:106-13.

14. Mullner M, Sterz F, Binder M, Schreiber W, Deimel A, Laggner AN. Blood glucose concentration after cardiopulmonary resuscitation influences functional neurological recovery in human cardiac arrest survivors. J Cereb Blood Flow Metab. 1997:17:430-6.

15. Nurmi J, Boyd J, Anttalainen N, Westerbacka J, Kuisma M. Early increase in blood glucose in patients resuscitated from out-of-hospital ventricular fibrillation predicts poor outcome. Diabetes Care. 2012;35:510-2.

16. Skrifvars MB, Pettila V, Rosenberg PH, Castren M. A multiple logistic regression analysis of in-hospital factors related to survival at six months in patients resuscitated from out-of-hospital ventricular fibrillation. Resuscitation. 2003;59:319-28.

17. Beiser DG, Carr GE, Edelson DP, Peberdy MA, Hoek TL. Derangements in blood glucose following initial resuscitation from in-hospital cardiac arrest: a report from the national registry of cardiopulmonary resuscitation. Resuscitation. 2009:80:624-30

18. Calle PA, Buylaert WA, Vanhaute OA. Glycemia in the post-resuscitation period. The Cerebral Resuscitation Study Group. Resuscitation. 1989:17:S181-8. Discussion S199-206.

19. Daviaud F, Dumas F, Demars N, Geri G, Bougle A, Morichau-Beauchant T, et al. Blood glucose level and outcome after cardiac arrest: insights from a large registry in the hypothermia era. Intensive Care Med. 2014;40:855-62.

20. Cueni-Villoz N, Devigili A, Delodder F, Cianferoni S, Feihl F, Rossetti AO, et al. Increased blood glucose variability during therapeutic hypothermia and outcome after cardiac arrest. Crit Care Med. 2011;39:2225-31.

21. Capes SE, Hunt D, Malmberg K, Gerstein HC. Stress hyperglycaemia and increased risk of death after myocardial infarction in patients with and without diabetes: a systematic overview. Lancet. 2000;355:773-8.

22. Capes SE, Hunt D, Malmberg K, Pathak P, Gerstein HC. Stress hyperglycemia and prognosis of stroke in nondiabetic and diabetic patients: a systematic overview. Stroke. 2001;32:2426-32.

23. Peberdy MA, Kaye W, Ornato JP, Larkin GL, Nadkarni V, Mancini ME, et al. Cardiopulmonary resuscitation of adults in the hospital: a report of 14720 cardiac arrests from the National Registry of Cardiopulmonary Resuscitation. Resuscitation. 2003:58:297-308.

24. Cummins RO, Chamberlain D, Hazinski MF, Nadkarni V, Kloeck W, Kramer E, et al. Recommended guidelines for reviewing, reporting, and conducting research on in-hospital resuscitation: the in-hospital 'Utstein style'. American Heart Association. Circulation. 1997;95:2213-39.

25. Jacobs I, Nadkarni V, Bahr J, Berg RA, Billi JE, Bossaert L, et al. Cardiac arrest and cardiopulmonary resuscitation outcome reports: update and simplification of the Utstein templates for resuscitation registries: a statement for healthcare professionals from a task force of the International Liaison Committee on Resuscitation (American Heart Association, European Resuscitation Council, Australian Resuscitation Council, New Zealand Resuscitation Council, Heart and Stroke Foundation of Canada, InterAmerican Heart Foundation, Resuscitation Councils of Southern Africa). Circulation. 2004:110:3385-97. 
26. Peberdy MA, Ornato JP, Larkin GL, Braithwaite RS, Kashner TM, Carey SM, et al. Survival from in-hospital cardiac arrest during nights and weekends. JAMA. 2008;299:785-92.

27. Jennett $B$, Bond M. Assessment of outcome after severe brain damage. Lancet. 1975;1:480-4.

28. Zou G. A modified poisson regression approach to prospective studies with binary data. Am J Epidemiol. 2004;159:702-6.

29. Zou GY, Donner A. Extension of the modified Poisson regression model to prospective studies with correlated binary data. Stat Methods Med Res. 2011;22:661-70

30. Chan PS, Nallamothu BK, Krumholz HM, Spertus JA, Li Y, Hammill BG, et al. Long-term outcomes in elderly survivors of in-hospital cardiac arrest. N Engl J Med. 2013;368:1019-26.

31. Chan PS, Nichol G, Krumholz HM, Spertus JA, Nallamothu BK. American Heart Association National Registry of Cardiopulmonary Resuscitation I. Hospital variation in time to defibrillation after in-hospital cardiac arrest. Arch Intern Med. 2009;169:1265-73.

32. Chan PS, Krumholz HM, Nichol G, Nallamothu BK. American Heart Association National Registry of Cardiopulmonary Resuscitation I. Delayed time to defibrillation after in-hospital cardiac arrest. N Engl J Med. 2008;358:9-17.

33. Meaney PA, Nadkarni VM, Kern KB, Indik JH, Halperin HR, Berg RA. Rhythms and outcomes of adult in-hospital cardiac arrest. Crit Care Med. 2010;38:101-8.

34. Egi M, Bellomo R, Stachowski E, French CJ, Hart GK, Taori G, et al. Hypoglycemia and outcome in critically ill patients. Mayo Clin Proc. 2010;85:217-24.

35. Investigators N-SS, Finfer S, Liu B, Chittock DR, Norton R, Myburgh JA, et al. Hypoglycemia and risk of death in critically ill patients. N Engl J Med. 2012;367:1108-18.

36. Sylvain HF, Pokorny ME, English SM, Benson NH, Whitley TW, Ferenczy CJ, et al. Accuracy of fingerstick glucose values in shock patients. Am J Crit Care. 1995:4:44-8.

37. Atkin SH, Dasmahapatra A, Jaker MA, Chorost MI, Reddy S. Fingerstick glucose determination in shock. Ann Intern Med. 1991;114:1020-4.

38. Thomas SH, Gough JE, Benson N, Austin PE, Stone CK. Accuracy of fingerstick glucose determination in patients receiving CPR. South Med J. 1994;87:1072-5.

39. Kagansky $\mathrm{N}$, Levy $\mathrm{S}$, Knobler $\mathrm{H}$. The role of hyperglycemia in acute stroke. Arch Neurol. 2001;58:1209-12.

40. Rovlias A, Kotsou S. The influence of hyperglycemia on neurological outcome in patients with severe head injury. Neurosurgery. 2000;46:335-42. Discussion 342-333.

41. Jeremitsky E, Omert LA, Dunham CM, Wilberger J, Rodriguez A. The impact of hyperglycemia on patients with severe brain injury. J Trauma. 2005;58:47-50.

42. Duckrow RB, Bryan Jr RM. Regional cerebral glucose utilization during hyperglycemia. J Neurochem. 1987;48:989-93.

43. Anderson RV, Siegman MG, Balaban RS, Ceckler TL, Swain JA. Hyperglycemia increases cerebral intracellular acidosis during circulatory arrest. Ann Thorac Surg. 1992;54:1126-30.

44. Rehncrona S, Rosen I, Siesjo BK. Brain lactic acidosis and ischemic cell damage: 1. biochemistry and neurophysiology. J Cereb Blood Flow Metab. 1981;1:297-311.

45. Longstreth Jr WT, Copass MK, Dennis LK, Rauch-Matthews ME, Stark MS, Cobb LA. Intravenous glucose after out-of-hospital cardiopulmonary arrest: a community-based randomized trial. Neurology. 1993;43:2534-41.

46. Monteiro S, Monteiro P, Goncalves F, Freitas M, Providencia LA. Hyperglycaemia at admission in acute coronary syndrome patients: prognostic value in diabetics and non-diabetics. Eur J Cardiovasc Prev Rehabil. 2010;17:155-9.

47. Hoxworth JM, Xu K, Zhou Y, Lust WD, LaManna JC. Cerebral metabolic profile, selective neuron loss, and survival of acute and chronic hyperglycemic rats following cardiac arrest and resuscitation. Brain Res. 1999:821:467-79.

\section{Submit your next manuscript to BioMed Central and take full advantage of:}

- Convenient online submission

- Thorough peer review

- No space constraints or color figure charges

- Immediate publication on acceptance

- Inclusion in PubMed, CAS, Scopus and Google Scholar

- Research which is freely available for redistribution

Submit your manuscript at www.biomedcentral.com/submit 